Please do not remove this page

RMIT

UNIVERSITY

\title{
Transforming growth factor-b regulation of proteoglycan synthesis in vascular smooth muscle: Contribution to lipid binding and accelerated atherosclerosis in diabetes
}

Yang, Sunday; Burch, Micah; Tannock, Lisa; Evanko, Stephen; Osman, Narin; Little, Peter

https://researchrepository.rmit.edu.au/esploro/outputs/9921857669601341/filesAndLinks?institution=61RMIT_INST\&index=null

Yang, S., Burch, M., Tannock, L., Evanko, S., Osman, N., \& Little, P. (2010). Transforming growth factor-b regulation of proteoglycan synthesis in vascular smooth muscle: Contribution to lipid binding and accelerated atherosclerosis in diabetes. Journal of Diabetes, 2(4), 233-242.

https://doi.org/10.1111/j.1753-0407.2010.00089.x

Document Version: Accepted Manuscript

Published Version: https://doi.org/10.1111/j.1753-0407.2010.00089.x

Repository homepage: https://researchrepository.rmit.edu.au

(c) 2010 Ruijin Hospital, Shanghai Jiaotong University School of Medicine and Blackwell Publishing Asia Pty Ltd

Downloaded On 2023/04/26 20:21:07 +1000 
Thank you for downloading this document from the RMIT Research Repository.

The RMIT Research Repository is an open access database showcasing the research outputs of RMIT University researchers.

RMIT Research Repository: http://researchbank.rmit.edu.au/

\section{Citation:}

Yang, S, Burch, M, Tannock, L, Evanko, S, Osman, N and Little, P 2010, 'Transforming growth factor-b regulation of proteoglycan synthesis in vascular smooth muscle:

Contribution to lipid binding and accelerated atherosclerosis in diabetes', Journal of Diabetes, vol. 2, no. 4, pp. 233-242.

See this record in the RMIT Research Repository at:

http://researchbank.rmit.edu.au/view/rmit:23354

Version: Accepted Manuscript

Copyright Statement: (c) 2010 Ruijin Hospital, Shanghai Jiaotong University School of Medicine and Blackwell Publishing Asia Pty Ltd

Link to Published Version:

http://dx.doi.org/10.1111/j.1753-0407.2010.00089.x 
Transforming growth factor- $\beta$ regulation of proteoglycan synthesis in vascular smooth muscle:

contribution to lipid binding and accelerated atherosclerosis in diabetes.

\author{
${ }^{1}$ Sundy N. Y.Yang,,${ }^{1,2}$ Micah L. Burch, ${ }^{3}$ Lisa R. Tannock, ${ }^{4}$ Stephen Evanko, and \\ ${ }^{1,2}$ Narin Osman ${ }^{1,2}$ Peter J. Little.
}

${ }^{1}$ BakerIDI Heart and Diabetes Institute, Diabetes and Cell Biology Laboratory, Melbourne, VIC, 3004, Australia

${ }^{2}$ Monash University School of Medicine (Alfred Hospital), Faculty of Medicine, Nursing and Health Sciences, Departments of Medicine and Immunology, Prahran VIC, 3004, Australia

${ }^{3}$ Division of Endocrinology and Molecular Medicine, University of Kentucky, Lexington, KY, USA,

${ }^{4}$ Benaroya Research Institute, Hope Heart Program, 1201 9th Ave, IN-RC, Seattle, WA., USA

Short running title: TGF- $\beta$, proteoglycans and atherosclerosis

Key words: macrovascular disease, Smads, response to retention

No. of Figures $=2$; No. of Tables $=0$

\title{
Correspondence:
}

Prof. Peter J. Little,

Head, Diabetes and Cell Biology Laboratory

BakerIDI Heart and Diabetes Institute

Postal Address: St. Kilda Rd Central, PO Box 6492, Melbourne, VIC 8008, Australia

Courier Address: $\quad 75$ Commercial Road, Melbourne, VIC 3004, Australia

Tel.: $\quad+61385321203$

Fax: $\quad+61385321100$

Email: peter.little@bakeridi.edu.au 


\begin{abstract}
Atherosclerosis is accelerated in the setting of diabetes but the factors driving this phenomenon remain elusive. Hyperglycemia leads to elevated levels of transforming growth factor- $\beta$ (TGF- $\beta$ ) and TGF- $\beta$ has been implicated as a factor in atherosclerosis. Given the established association between hyperglycemia and elevated TGF- $\beta$ it is plausible that elevated TGF- $\beta$ levels in diabetes play a pathogenic role in the development of accelerated atherosclerosis in diabetes. TGF- $\beta$ is a potent regulator of extracellular matrix synthesis, including many actions on proteoglycan synthesis which lead to increased binding to LDL and therefore potentially increased lipid retention in the vessel wall and accelerated atherosclerosis. TGF- $\beta$ signals through the canonical TGF- $\beta$ receptor I (T $\beta$ RI/Alk V) mediated phosphorylation of Smad transcription factors and is also known to involve, positively and negatively, interactions with the Mitogen Activated Protein (MAP) kinase pathways. This review will focus on the effects of TGF- $\beta$ on proteoglycan synthesis in vascular smooth muscle and particularly the signaling pathways through which TGF- $\beta$ exerts its effects because those pathways may be therapeutic targets for the prevention of pathological modifications in the proteoglycan component of the vessel wall in the vascular diseases of diabetes.
\end{abstract}




\section{Introduction}

Cardiovascular disease is the largest single cause of premature mortality in developed nations ${ }^{1}$. World-wide increases in obesity, metabolic syndrome and diabetes are driving higher rates of cardiovascular disease ${ }^{2,3}$. Individuals with diabetes have numerous acute issues such as hypoglycemic events however the main impact of diabetes on health is through the development of its microvascular (retinopathy, nephropathy, neuropathy and impotency) and macrovascular (myocardial infarction, stroke) complications ${ }^{4,5}$. The major manifestation of cardiovascular disease or coronary artery disease is an acute myocardial infarction leading to death or subsequently heart failure. Atherosclerosis, the underlying pathology of macrovascular disease, is accelerated by the plasma milieu and other factors associated with diabetes resulting in higher levels of cardiovascular disease in this group ${ }^{6,7}$. Acute ischemic events have a more profound effect in people with diabetes because of the more pervasive vascular disease and the higher susceptibility of the myocardium to the effects of ischemia ${ }^{8,9}$. The underlying pathology is atherosclerosis, the slow accumulation of cholesterol in the sub-endothelium of the artery wall and the development over several decades of complex lesions termed plaques ${ }^{7,10-14}$. Some plaques are labile and the rupture of such so-called vulnerable plaques leads to the adverse clinical event ${ }^{15,16}$. The extended risk factors include cigarette smoking, hypertension, hyperlipidemia and hyperglycemia and nonmodifiable factors such as age and genetic predisposition ${ }^{17}$. Medical therapies are based on lowering risk factors and anti-hypertensives and anti-hyperlipidemia agents are quite efficacious ${ }^{18,19}$. The role of glucose and hyperglycemia in driving accelerated atherosclerosis and increased rates of CVD are well established both epidemiologically ${ }^{20}$ and investigationally such as the recent study of Intravascular 
Ultrasound (IVUS) of plaque progression in people with diabetes ${ }^{21}$. However, in contrast to the established efficacy of agents which lower plasma cholesterol and blood pressure the role of anti-hyperglycemic agents in preventing cardiovascular disease is highly controversial ${ }^{22,23}$. The reasons for this are most perplexing ${ }^{24}$. Thus, in spite of multiple therapies, rates of cardiovascular events are still high and a better understanding of the drivers of atherosclerosis in the setting of diabetes is required and this will hopefully lead to the identification of new targets and ultimately new treatment modalities.

There are several theories in relation to the origins of atherosclerosis. These include the Response to Injury hypothesis of Ross and Glomset ${ }^{25}$, Response to Retention Hypothesis of Tabas, Williams and later Boren ${ }^{13,26}$, the oxidation hypothesis ${ }^{27}$ and the role of hyperglycemia and Advanced Glycation End (AGE) products ${ }^{28,29}$. The major processes initiating atherosclerosis are the initial deposition and accumulation of lipid in the vessel wall ${ }^{30}$ and the subsequent inflammatory response which ultimately generates the complex and sometimes labile plaques 11,12,15,16. Nakashima et al. ${ }^{31}$ demonstrated that in human coronary arteries the deposition of lipid occurs before the inflammatory response and the deposited apolipoproteins associated with the lipid co-localize with proteoglycans specifically biglycan and decorin ${ }^{31}$. Thus the extracellular matrix and in particular the lipidbinding proteoglycan component is altered in the neointima of atherosclerosis susceptible arteries and it forms the permissive environment for the initiation of atherosclerosis ${ }^{14,32,33}$. Whether or not the initial lipid retention by proteoglycans is the forerunner of the inflammatory response or the inflammatory response is independent is unknown. The former alternative seems more likely and if so then proteoglycan to 
lipid interaction is integral to the initiation of atherosclerosis and potentially represents a therapeutic target for the prevention of the disease process ${ }^{34,35}$.

The impact of the factors associated with diabetes on the production of proteoglycans by VSMCs has been investigated in detail by Tannock, Little and colleagues ${ }^{36-39}$. Surprisingly, many of the obvious factors, including hyperglycemia, have no effect on proteoglycan synthesis and structure under the conditions so far investigated ${ }^{36,37}$. Glucosamine, investigated as a component of the hexosamine pathway, has the potential to act as a precursor for glycosaminoglycan (GAG) synthesis and thus increase proteoglycan and GAG chain synthesis ${ }^{40}$. Our studies actually found that it has the opposite effect and exogenous glucosamine causes concentration dependent inhibition of GAG elongation ${ }^{36}$ which we later showed to be due to competition with glucose uptake leading to cellular ATP depletion ${ }^{38}$. Elevated free fatty acids are a component of the early dysmetabolic status of diabetes ${ }^{41}$ and free fatty acids also have a modest effect on proteoglycan synthesis in VSMC ${ }^{42}$.

The major effect of the diabetic milieu appears to be indirect due to the action of high glucose concentrations to stimulate the secretion of TGF- $\beta^{37,43}$. The hyperglycemia in patients with Type 2 diabetes leads to increased renal production of TGF- $\beta^{43}$. TGF- $\beta$ is a potent regulator of extracellular matrix synthesis, including many actions on proteoglycan synthesis ${ }^{39,44-47}$. TGF- $\beta$ induces changes in the proteoglycans secreted by VSMCs leading to increased binding to LDL ${ }^{39}$ and therefore potentially increased lipid retention in the vessel wall and accelerated atherosclerosis ${ }^{14}$. TGF- $\beta$ has been implicated in many diseases including tumor metastasis and renal and cardiac fibrosis ${ }^{48-50}$. Hyperglycemia has also been linked to activation of TGF- $\beta$ signaling pathways regulating processes associated with the complications of diabetes ${ }^{51}$. TGF- $\beta$ is strongly implicated in atherosclerosis and it is 
highly expressed in atherosclerotic plaques (see Fig. 1). TGF- $\beta$ and its receptors are present in atherosclerotic lesions ${ }^{52}$ and play an important role in regulating vessel proteoglycan synthesis and lipoprotein retention ${ }^{52,53}$. Thus, given the established association between hyperglycemia and elevated TGF- $\beta^{43}$, it is plausible that elevated TGF- $\beta$ levels in diabetes plays a pathogenic role in the development of accelerated atherosclerosis in diabetes. On this basis we have reviewed the actions of TGF- $\beta$ on proteoglycan synthesis in VSMC as a surrogate for the effects of the diabetic milieu on the vascular extracellular matrix. This review will focus on the effects of TGF- $\beta$ on proteoglycan synthesis in vascular smooth muscle and particularly the signaling pathways through which TGF- $\beta$ exerts its effects because those pathways may be therapeutic targets for the prevention of pathological modifications in the proteoglycan component of the vessel wall in diabetic vascular disease.

\section{TGF- $\beta$ and TGF- $\beta$ receptors}

TGF- $\beta$ is a multifunctional growth factor that controls cellular processes involved in proliferation, differentiation, apoptosis, extracellular matrix accumulation and the immune system $49,50,54$. The TGF- $\beta$ superfamily of ligands include: Bone morphogenetic proteins (BMPs), Growth and differentiation factors (GDFs), Antimüllerian hormone $(\mathrm{AMH})$, Activin, Nodal and TGF- $\beta \mathrm{s}^{55}$. TGF- $\beta$ is a secreted protein that exists in three isoforms called TGF- $\beta 1$, TGF- $\beta 2$ and TGF- $\beta 3$. Three isoforms are highly conserved in mammals, and deletion of the isoforms in mice leads to distinct phenotypes ${ }^{56-58}$. All three TGF- $\beta$ s are synthesized as precursor molecules containing an N-terminal propeptide region in addition to the TGF- $\beta$ homodimer ${ }^{59}$. The N-terminal signal peptide (propeptide region) consists of a 20-30 amino acid domain called latency associated peptide (LAP) required for secretion from the cell 
and a 112-114 amino acid C-terminal region that becomes the mature TGF- $\beta$ molecule following its release from the propeptide region by proteolytic cleavage ${ }^{60}$. TGF- $\beta$ homodimer interacts with a LAP forming a complex called Small Latent Complex (SLC). This complex remains in the cell until it is bound by a protein called Latent TGF- $\beta$-Binding Protein (LTBP), forming a larger complex called Large Latent Complex (LLC). It is LLC that get secreted to the extracellular matrix ${ }^{61}$. In most cases, before the LLC is secreted, the TGF- $\beta$ precursor is cleaved from the propeptide but remains attached to it by noncovalent bonds ${ }^{62}$. After its secretion, it remains in the extracellular matrix as an inactivated complex containing both the LTBP and the LAP which need to be further processed in order to release active TGF- $\beta^{63}$.

TGF- $\beta$ receptors are the major family of cell surface receptors which are serine/threonine kinases but they also possess weak tyrosine kinase activity ${ }^{64}$. They exist in several different isoforms that can be homo- or heterodimeric ${ }^{65}$. Receptor types I (T $\beta R I)$ and II (T $\beta R I I)$ are signaling receptors consisting of an N-terminal extracellular ligand binding domain, a transmembrane region and a C-terminal serine/threonine kinase domain. T $\beta$ RI, but not T $\beta$ RII receptors contain a GS domain (cytosolic and immediately N-terminal to the kinase domain) which consists of a series of about thirty glycine-serine repeats ${ }^{54}$. TGF- $\beta$ receptor type III is the most abundant and a non-signaling receptor which plays a role in transferring TGF- $\beta$ to its signaling receptors and has a high affinity for both TGF- $\beta 1$ and TGF- $\beta 2{ }^{66}$. Type III receptors are membrane proteoglycans that carry heparan and chondroitin sulfate GAG chains. The binding site for TGF- $\beta$ resides in the $100-120-\mathrm{kDa}$ core polypeptide of this receptor. The type III receptor is highly sensitive to cleavage by trypsin. Trypsin action releases the GAG-containing domain of the receptor leaving a $60-\mathrm{kDa}$ membrane-associated domain that contains the cross-linked ligand ${ }^{66}$. 
In mammals there are seven known type I receptors and five type II receptors ${ }^{67}$. Signaling begins with a TGF- $\beta$ ligand binding to a constituitively active type II receptor dimer, which recruits a type I receptor dimer forming a hetero-tetrameric complex with the ligand on the cell surface. The binding of a TGF- $\beta$ family ligand causes the rotation of the receptors so that their cytoplasmic kinase domains are arranged in a catalytically favorable orientation. This enables the type II receptor to phosphorylate multiple serine and threonine residues in the GS region of the type I receptor.

TGF- $\beta$ signals via the T $\beta$ RI/Alk V receptor and the canonical Smad pathway involving extreme C-terminal phosphorylation of receptor-regulated (R)-Smad transcription factors and translocation of Smad complexes to the nucleus where they regulate transcription ${ }^{50,54}$. T $\beta R I$ can also activate Mitogen Activated Protein (MAP) kinases leading to the phosphorylation of R-Smads in their linker region, a response that can inhibit or promote TGF- $\beta$ signaling ${ }^{68}$. The latter pathway is known somewhat incongruously as non-Smad or Smad independent signaling notwithstanding that it involves ultimately Smad phosphorylation.

\section{The Smad family and TGF-ß signaling via phosphorylation of Smad carboxyl terminal}

The activated type I receptor phosphorylates cytoplasmic proteins of the Cterminal regions of Smad family. Smads are a class of proteins that modulate the activity of TGF- $\beta$ ligands and consist of three domains: (1) an N-terminal Madhomology 1 (MH1) domain which carries nuclear localization signals (NLS) and a DNA-binding domain; (2) a linker region of variable sequence and length that interact with prolyl-isomerases and ubiquitin ligases; (3) a C-terminal MH2 domain which 
binds to type I receptor and mediates Smad homo- and hetero-oligomerization as well as mediates the transactivation of nuclear Smad complexes ${ }^{69}$. There are three classes of Smad: (1) the receptor-regulated Smads (R-Smad) which include Smad1, Smad2, Smad3, Smad5 and Smad9 (sometimes referred to as Smad8) ${ }^{70}$; (2) the commonmediator Smad (co-Smad) which includes only Smad4, which interacts with R-Smads to participate in signaling ${ }^{71}$; (3) The antagonistic or inhibitory Smads (I-Smad) which include Smad6 and Smad7, which block the activation of R-Smads and Co-Smads and can also signal-terminating initiate degradation ${ }^{72}$. There are five receptor regulated Smads. TGF- $\beta$ s, Activins, Nodals and some GDFs are mediated by Smad 2 and Smad3, while BMPs, AMH and a few GDFs are mediated by Smad1, Smad5 and Smad9.

The C-terminal phosphorylation of receptor activated R-Smads allows them to bind the co-Smad, Smad 4. This resulting R-Smad/co-Smad complex which consist of trimers of two R-Smads and one Smad4, is then imported into the nucleus where they act as transcription factors and participate in the regulation of target gene expression $^{50}$.

\section{TGF-ß signaling via phosphorylation of the Smad2 linker region}

TGF- $\beta$ signaling is also known to involve positively and negatively in interaction with Mitogen Activated Protein (MAP)/ Extracellular signal-Regulated Kinases (ERK) pathway ${ }^{50,54,73}$. TGF- $\beta$ stimulates the phosphorylation of ERK $1 / 2{ }^{73}$; the activated ERK then phosphorylates Smad2 on threonine residues and possibly serine residues in the linker region which can induce the expression of the inhibitory I-Smads, Smad 6 and Smad7, that can hinder the translocation of the Smad2 into the nucleus and resistance to TGF- $\beta$ signaling ${ }^{73}$. 


\section{Proteoglycans}

Proteoglycans are glycosylated proteins which have covalently attached highly anionic GAGs ${ }^{74}$. Many forms of proteoglycans are present in all extracellular matrices of connective tissues including the blood vessel wall, where they are a component of the extracellular matrix as well as a cell-surface component of vascular cells. The major biological function of proteoglycans derives from the physicochemical characteristics of the core protein and carbohydrate components of the molecule. Core proteins determine the cellular location and serve as scaffolds for the GAG chains and the highly ionic chains determine physical properties of tissues and bind factors including growth factors and apolipoproteins. The GAG chains are long, linear carbohydrate polymers that are highly negatively charged under physiological conditions, due to the occurrence of sulfate and uronic acid groups. The complementary roles of core protein and GAG are exemplified by the observation that binding of low-density lipoprotein (LDL) to GAG chains of intact proteoglycans occurs with an order of magnitude higher affinity than the binding to free GAG chains 75 .

Proteoglycans can be categorized depending upon the nature of their GAG chains. These chains may be: chondroitin sulfate, decorin sulfate, heparan sulfate and keratan sulfate. Proteoglycans have distinct biological functions and their involvement in many aspects of cell and tissue activities has been demonstrated. For example, aggrecan, forms a substantial structural component of cartilage and is composed of both decorin sulfate and keratan sulfate GAG chains. Large chondroitin sulfate proteoglycan, versican, is prominent in blood vessels ${ }^{76}$. The smaller leucine-rich proteoglycans includes biglycan and decorin, which are widely distributed in many connective tissues, may have functions in regulating collagen fibril formation and in 
modifying the activity of TGF- $\beta^{77}$. Perlecan, the major heparan sulfate proteoglycan in the glomerular basement membrane, may play an important role as the major anionic site responsible for the charge selectivity in glomerular filtration ${ }^{78}$.

Vascular smooth muscle cells isolated and passaged from human vessels, secrete predominantly the small chondroitin/decorin sulfate proteoglycans: biglycan, decorin, lesser amounts of versican and heparan sulfate proteoglycan, perlecan ${ }^{79}$. TGF- $\beta^{75}$ and oxidized LDL ${ }^{80}$ regulate the GAG chains elongation and the proportion of the chondroitin/decorin sulfate proteoglycans in the component mixture of secreted proteoglycans. These effects lead to enhanced binding of proteoglycans to atherogenic apolipoproteins ${ }^{81}$. In the initiation of atherosclerosis, the growth factor-modified biglycan with elongated GAG chains has been termed by us as "hyperelongated biglycan" 25 . The modifications to GAGs on chondroitin sulfate and decorin sulfate proteoglycans increases the binding of GAGs to apolipoproteins ${ }^{75,81,82}$; the hydrolytic and proteolytic modifications of apolipoproteins increase the binding strength of GAGs to LDL ${ }^{80,83}$.

\section{Actions of TGF- $\beta$ on proteoglycan synthesis in vascular smooth muscle}

\section{Actions of TGF- $\beta$ on proteoglycan synthesis}

TGF- $\beta$ stimulates proteoglycan synthesis, specifically the expression of biglycan and an elongation of its decorin sulfate (DS) GAG chains and this results in an increased binding of the proteoglycan to LDL ${ }^{39,44,46,47}$. In very early studies, Wight and colleagues ${ }^{44,45}$ found that TGF- $\beta$ causes a 3.3 -fold increase in radiosulfate incorporation into biglycan in monkey arterial smooth muscle cells, but as expected it 
had no effect on core protein size. Northern blotting analysis also revealed a more than two fold increase in biglycan mRNA expression ${ }^{45}$. TGF- $\beta$ had no appreciable effect on decorin core protein synthesis or GAG elongation on decorin ${ }^{45}$. We have confirmed and extended these findings in human VSMCs ${ }^{46,47}$. TGF- $\beta$ increases radiosulfate incorporation into biglycan, associated with a marked increase in proteoglycan size which is specifically associated with an increase in the size of the GAG chains ${ }^{39,47}$. TGF- $\beta$ also increases $\left[{ }^{35} \mathrm{~S}\right]$-methionine/cysteine incorporation indicating an increase in core protein synthesis ${ }^{46}$ and consistent with the induction of biglycan mRNA first described by Schonherr et al. ${ }^{45}$. All responses to TGF- $\beta$ are concentration-dependently inhibited by the TßRI/Alk V inhibitor SB431542 indicating that they arise from T $\beta \mathrm{RI} / \mathrm{Alk} \mathrm{V}^{46}$.

\section{TGF- $\beta$ receptor signaling pathway regulating biglycan synthesis}

TGF- $\beta$ can also activate MAP kinases leading to downstream signaling completely independent of Smads but also causing phosphorylation of Smads in the linker region ${ }^{50}$ a response originally associated with the inhibition of Smad translocation to the nucleus and this is antagonistic to TGF- $\beta$ signaling ${ }^{73}$. We recently investigated the ability of TGF- $\beta$ to stimulate the phosphorylation of $\mathrm{p} 38$, Extracellular signal-Regulated Kinases (ERK) and Jun N-terminal Kinase (JNK) MAP kinases as well as Smad2 phosphorylation at both its C-terminal and in the linker region ${ }^{47}$. TGF- $\beta$ stimulated the phosphorylation of all three MAP kinases ${ }^{47}$. Pharmacological inhibition of ERK and p38 MAP kinase blocked TGF- $\beta$ mediated GAG elongation and expression of biglycan whereas inhibition of JNK had no effect. Inhibition of ERK and p38 but not JNK MAP kinases attenuated the effect of TGF- $\beta$ to increase phosphorylation of Smad2 linker region ${ }^{47}$. High levels of phosphorylation 
of Smad2 linker region were detected in a nuclear fraction of TGF- $\beta$ treated cells implying that this response was not antagonistic to TGF- $\beta$ signaling. Thus, TGF- $\beta$ signaling via ERK and p38 MAP kinases and leading to the phosphorylation of the linker region of Smad2 mediates its effects of TGF- $\beta$ on biglycan synthesis and GAG elongation in human vascular smooth muscle cells ${ }^{47}$. We have also demonstrated that the size of the effect mediated by the signaling pathways is sufficient to alter binding to LDL because the binding of radiolabelled proteoglycans to normal human LDL is reduced in proteoglycan harvested from cells treated with inhibitors of the TGF- $\beta$ receptor $(\mathrm{T} \beta \mathrm{RI})$ or p38 MAP kinase ${ }^{46}$.

\section{Consequences of TGF- $\beta$ stimulated proteoglycan synthesis: increased}

\section{lipid binding}

TGF- $\beta$ has two actions on proteoglycan synthesis which can enhance the atherogenicity of the extracellular matrix. TGF- $\beta$ stimulates the expression of biglycan which is the proteoglycan most closely associated with lipid binding in early human atherosclerosis ${ }^{30}$ and TGF- $\beta$ also stimulates the elongation of GAG chains leading to hyperelongated chains which show enhances binding in to LDL ${ }^{14,39,84}$. Highly anionic (sulfated and carboxylated) GAG chains on proteoglycans bind to a multitude of molecules but practically and of interest to the development of atherosclerosis they bind to cationic residues on the apolipoproteins (B100) on human LDL $^{85,86}$. Lipids bind to the GAGs in the vessel wall ${ }^{87}$. Due to the complex nature of the interacting species it is difficult to describe the interaction in classical receptor-binding terms but when an equal quantity of radiolabelled proteoglycan core proteins from control and TGF- $\beta$ treated cells is added to an in vitro gel mobility shift 
assay then the latter show higher affinity binding as evidenced by a shift to the left of the binding isotherm ${ }^{39}$. The rate limiting step for passages of lipoproteins through the vessel wall is the release from the wall to the lymph so an increase in binding affinity will delay the transition of the lipid and ultimately induce the inflammatory response that generates the complex plaques ${ }^{88}$.

As described above, TGF- $\beta$ signaling involves Smad transcription factors acting through the canonical $\mathrm{C}$ terminal phosphorylation pathways but also as shown recently by us potentially via the TGF- $\beta$-stimulated MAP kinase (p38 and Erk) mediated phosphorylation of the linker region of $\operatorname{Smad} 2{ }^{47}$. Multiple other hormones and growth factors activate MAP kinases in VSMCs and these have the potential to cause Smad linker phosphorylation. Such a response might synergize with the actions of TGF- $\beta$ in diabetes and indeed we have reported that the actions of TGF- $\beta$ and PDGF are additive in causing GAG elongation on biglycan ${ }^{34}$ and by extrapolation causing increased binding to LDL. Thus, hyperglycemia driven increased level of TGF- $\beta$ can synergize with other factors known to be elevated in diabetes to drive hyperelongation of GAG chains on lipid binding proteoglycans (see schema in Fig. 2) and thus has the potential to be the driving factor and the link between hyperglycemia and accelerated development of atherosclerosis in diabetes ${ }^{89}$

\section{Conclusions}

Proteoglycans are complex molecules being comprised of both protein and carbohydrate moieties. These entities have completely different synthetic processes consistent with normal cell biology of the synthesis of proteins and GAGs ${ }^{40,90}$. All of these features can be involved in pathology because growth factors can alter the 
proteoglycan composition of the extracellular matrix by altering the relative expression of proteoglycan core proteins or independently by causing the elongation of the GAG chains, known as hyperelongation ${ }^{14}$. Each of these processes regulating core proteins and GAG synthesis is activated by signaling pathways which are sometimes similar but can also be completely distinct ${ }^{91}$. Considerable progress has been made in revealing the signaling pathways that control the synthesis and structure of proteoglycans in vascular smooth muscle from the hormone and growth factors ${ }^{39,92-94}$, metabolic factors ${ }^{36}$ through to the involvement of transcription factors ${ }^{95}$ that regulate the genes that control growth factor stimulated proteoglycan synthesis. Amongst these factors TGF- $\beta$ is one of the most prominent activators of proteoglycan syntheses and it leads to increased binding to LDL. Given the established association between hyperglycemia and elevated TGF- $\beta$ we have speculated that elevated TGF- $\beta$ levels in diabetes play a pathogenic role in the development of accelerated atherosclerosis in diabetes. Blocking growth factor actions on proteoglycan synthesis with many known cardiovascular and diabetes drugs attenuates lipid binding and potential provides pleiotropic actions which assist in the prevention of atherosclerosis 96,97. These signaling pathways have the potential to be therapeutic targets for vascular diseases such as atherosclerosis especially when targeted by highly specific agents 34,35. Further studies will reveal the potential for these pathways to represent therapeutic targets that may be successfully exploited without interfering with the normal physiological functions of TGF- $\beta$. 


\section{Figures}

Figure 1. Atherosclerotic plaques show expression of TGF- $\beta$. Sections of abdominal aorta from a hypercholesterolemia non-human primate, Macaca nemestrina, and containing advanced fibrous plaques were immunostained with antibodies specific for control IgG (left panel) and with TGF- $\beta 1$ (right panel). Positive staining for TGF- $\beta 1$ was seen in macrophages in the core of the lesion as well as macrophages scattered in the fibrous cap and near the luminal surface. Magnification, X60.

Reprinted from Am J Pathol 1998, 152:533-546 with permission from the American Society for Investigative Pathology.
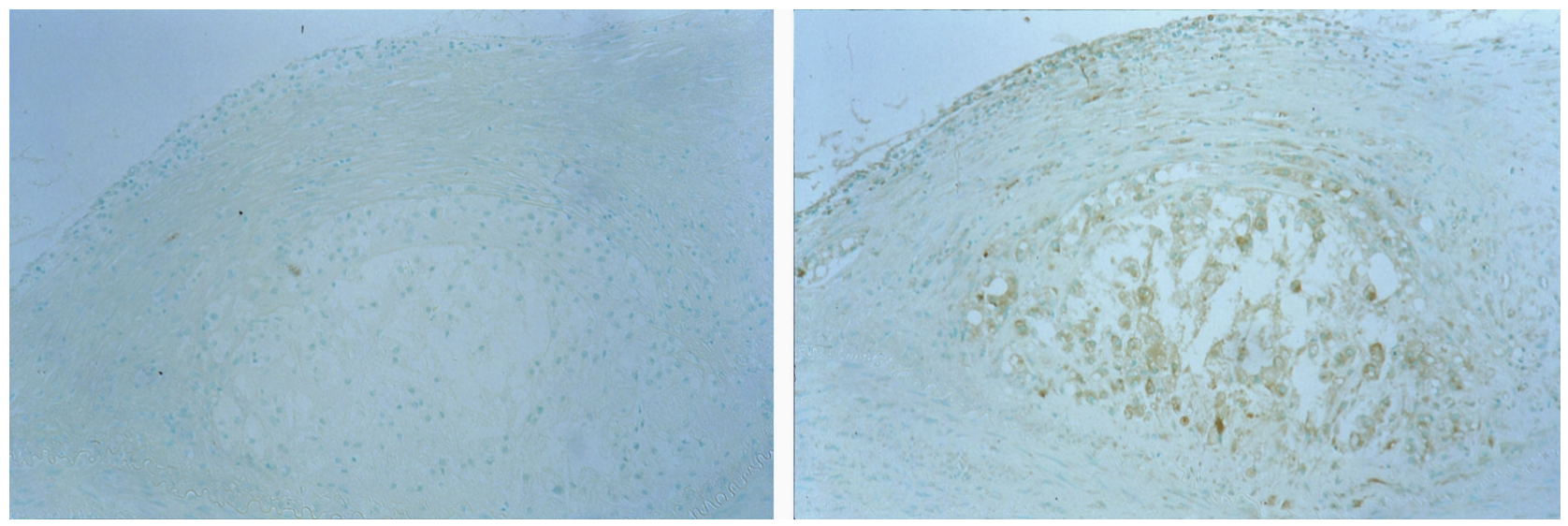
Figure 2. Schema showing our current knowledge of the signaling pathway through which Transforming Growth Factor (TGF)- $\beta$ stimulates changes in the synthesis and structure of proteoglycans secreted by vascular smooth muscle cells. These changes lead to increased in vitro binding of proteoglycan to LDL and given the established relationship between hyperglycemia and elevated TGF- $\beta$ levels, these effects potentially underlie the increased atherosclerosis observed in people with diabetes. The pathway leading to the stimulation of biglycan synthesis involves the canonical as well as the MAP kinase linker region phosphorylation pathway (see text for details and references). Erk: Extracellular regulated kinase; p38: p38 Mitogen Activated Protein (MAP) kinases; T $\beta$ RI and T $\beta$ RII are the Type I and II TGF- $\beta$ receptors, respectively. Smad is the Smad transcription factors as part of the T $\beta R I$ signaling pathways.

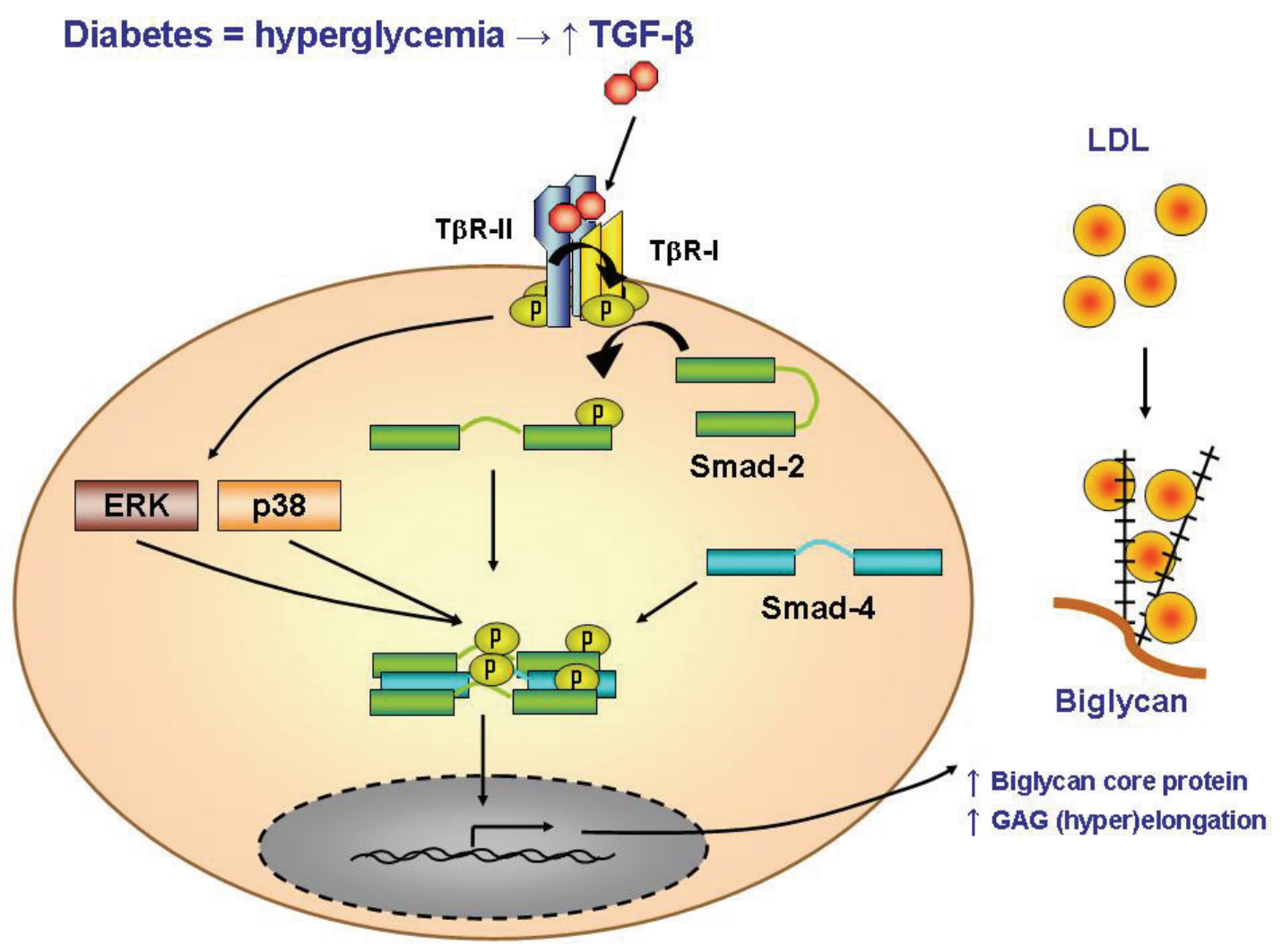




\section{Acknowledgments}

This study was supported by National Health and Medical Research Council project grant $\left({ }^{\#} 472611\right)$ (PJL) and Fellowship (PJL) and a National Heart Foundation of Australia grant-in-aid (PJL). 


\section{References}

1. A. Hozawa, A.R. Folsom, A.R. Sharrett, and L.E. Chambless, Absolute and attributable risks of cardiovascular disease incidence in relation to optimal and borderline risk factors: comparison of African American with white subjects-Atherosclerosis Risk in Communities Study. Arch Intern Med 2007; 167: 5739.

2. P.Z. Zimmet, D.J. McCarty, and M.P. de Courten, The global epidemiology of noninsulin-dependent diabetes mellitus and the metabolic syndrome. $J$ Diabetes Complications 1997; 11: 60-8.

3. K.J. Hunt, R.G. Resendez, K. Williams, S.M. Haffner, and M.P. Stern, National Cholesterol Education Program versus World Health Organization metabolic syndrome in relation to all-cause and cardiovascular mortality in the San Antonio Heart Study. Circulation 2004; 110: 1251-7.

4. A. Pfeiffer, and H. Schatz, Diabetic microvascular complications and growth factors. Experimental and Clinical Endocrinology and Diabetes 1995; 103: 714.

5. A.I. Adler, I.M. Stratton, H.A. Neil, et al., Association of systolic blood pressure with macrovascular and microvascular complications of type 2 diabetes (UKPDS 36): prospective observational study. BMJ 2000; 321: 412-9.

6. S.S. Soedamah-Muthu, J.H. Fuller, H.E. Mulnier, et al., All-cause mortality rates in patients with type 1 diabetes mellitus compared with a non-diabetic population from the UK general practice research database, 1992-1999. Diabetologia 2006: 1-7.

7. J. Nigro, N. Osman, A.M. Dart, and P.J. Little, Insulin Resistance and Atherosclerosis. Endocr Rev 2006; 27: 242-259.

8. S.M. Haffner, S. Lehto, T. Ronnemaa, K. Pyorala, and M. Laakso, Mortality from coronary heart disease in subjects with type 2 diabetes and in nondiabetic subjects with and without prior myocardial infarction. $N$ Engl J Med 1998; 339: 229-34.

9. G. Howard, D.H. O'Leary, D. Zaccaro, et al., Insulin sensitivity and atherosclerosis. The Insulin Resistance Atherosclerosis Study (IRAS) Investigators. Circulation 1996; 93: 1809-17.

10. R. Ross, The pathogenesis of atherosclerosis. N Engl J Med 1986; 314: 488-500.

11. R. Ross, Atherosclerosis--an inflammatory disease. N Engl J Med 1999; 340: 11526.

12. P. Libby, Vascular biology of atherosclerosis: overview and state of the art. $A m J$ Cardiol 2003; 91: 3A-6A.

13. K.J. Williams, and I. Tabas, The response-to-retention hypothesis of early atherogenesis. Arterioscler Thromb Vasc Biol 1995; 15: 551-61.

14. P.J. Little, N. Osman, and K.D. O'Brien, Hyperelongated biglycan: the surreptitious initiator of atherosclerosis. Current Opinion in Lipidology 2008; 19: 448-454.

15. M.J. Davies, Stability and instability: two faces of coronary atherosclerosis. The Paul Dudley White Lecture 1995. Circulation 1996; 94: 2013-20.

16. E. Falk, Morphologic features of unstable atherothrombotic plaques underlying acute coronary syndromes. Am J Cardiol 1989; 63: 114E-120E. 
17. R. Cooper, J. Cutler, P. Desvigne-Nickens, et al., Trends and disparities in coronary heart disease, stroke, and other cardiovascular diseases in the United States: findings of the national conference on cardiovascular disease prevention. Circulation 2000; 102: 3137-47.

18. P. Gaede, P. Vedel, N. Larsen, et al., Multifactorial intervention and cardiovascular disease in patients with type 2 diabetes. $N$ Engl $J$ Med 2003; 348: 383-93.

19. A.V. Finn, M.C. Kramer, M. Vorpahl, F.D. Kolodgie, and R. Virmani, Pharmacotherapy of coronary atherosclerosis. Expert Opin Pharmacother 2009; 10: 1587-603.

20. J.A. Beckman, M.A. Creager, and P. Libby, Diabetes and atherosclerosis: epidemiology, pathophysiology, and management. Jama 2002; 287: 2570-81.

21. C. Berry, S. Noble, J.C. Gregoire, et al., Glycaemic status influences the nature and severity of coronary artery disease. Diabetologia 53: 652-8.

22. S.E. Nissen, and K. Wolski, Effect of rosiglitazone on the risk of myocardial infarction and death from cardiovascular causes. $N$ Engl J Med 2007; 356: 2457-71.

23. G.A. Diamond, L. Bax, and S. Kaul, Uncertain Effects of Rosiglitazone on the Risk for Myocardial Infarction and Cardiovascular Death. Ann Intern Med 2007.

24. A. Chait, and K.E. Bornfeldt, Diabetes and atherosclerosis: is there a role for hyperglycemia? J Lipid Res 2009; 50 Suppl: S335-9.

25. R. Ross, and J.A. Glomset, The pathogenesis of atherosclerosis (second of two parts). N Engl J Med 1976; 295: 420-5.

26. I. Tabas, K.J. Williams, and J. Boren, Subendothelial lipoprotein retention as the initiating process in atherosclerosis: update and therapeutic implications. Circulation 2007; 116: 1832-44.

27. J.A. Berliner, M. Navab, A.M. Fogelman, et al., Atherosclerosis: basic mechanisms. Oxidation, inflammation, and genetics. Circulation 1995; 91: 2488-96.

28. M. Brownlee, Biochemistry and molecular cell biology of diabetic complications. Nature 2001; 414: 813-20.

29. M.E. Cooper, F. Bonnet, M. Oldfield, and K. Jandeleit-Dahm, Mechanisms of diabetic vasculopathy: an overview. Am J Hypertens 2001; 14: 475-86.

30. Y. Nakashima, H. Fujii, S. Sumiyoshi, T.N. Wight, and K. Sueishi, Early human atherosclerosis: accumulation of lipid and proteoglycans in intimal thickenings followed by macrophage infiltration. Arterioscler Thromb Vasc Biol 2007; 27: 1159-65.

31. Y. Nakashima, T.N. Wight, and K. Sueishi, Early atherosclerosis in humans: role of diffuse intimal thickening and extracellular matrix proteoglycans. Cardiovasc Res 2008; 79: 14-23.

32. T.N. Wight, Proteoglycans in pathological conditions: atherosclerosis. Fed Proc 1985; 44: 381-5.

33. G. Camejo, E. Hurt-Camejo, U. Olsson, and G. Bondjers, Proteoglycans and lipoproteins in atherosclerosis. Curr Opin Lipidol 1993; 4: 385-391.

34. P.J. Little, M.L. Ballinger, and N. Osman, Vascular wall proteoglycan synthesis and structure as a target for the prevention of atherosclerosis. Vascular Health Risk Management 2007; 3: 1-8. 
35. M.L. Ballinger, J. Nigro, K.V. Frontanilla, A.M. Dart, and P.J. Little, Regulation of glycosaminoglycan structure and atherogenesis. Cell Mol Life Sci 2004; 61: 1296-306.

36. L. Tannock, P.J. Little, T.N. Wight, and A. Chait, Arterial smooth muscle cell proteoglycans synthesized in the presence of glucosamine demonstrate reduced binding to LDL. J Lipid Res 2002; 43: 149-157.

37. P. Wilson, K. Drennon, and L.R. Tannock, Regulation of vascular proteoglycan synthesis by metabolic factors associated with diabetes. J Investig Med 2007; 55: $18-25$.

38. P.J. Little, K.D. Drennon, and L.R. Tannock, Glucosamine inhibits the synthesis of glycosaminoglycan chains on vascular smooth muscle cell proteoglycans by depletion of ATP. Arch Physiol Biochem 2008; 114: 120-6.

39. P.J. Little, L. Tannock, K.L. Olin, A. Chait, and T.N. Wight, Proteoglycans synthesized by arterial smooth muscle cells in the presence of transforming growth factor-betal exhibit increased binding to LDLs. Arterioscler Thromb Vasc Biol 2002; 22: 55-60.

40. J.E. Silbert, and G. Sugumaran, Biosynthesis of chondroitin/dermatan sulfate. IUBMB Life 2002; 54: 177-86.

41. P. Arner, Insulin resistance in type 2 diabetes: role of fatty acids. Diabetes Metab Res Rev 2002; 18 Suppl 2: S5-9.

42. U. Olsson, G. Bondjers, and G. Camejo, Fatty acids modulate the composition of extracellular matrix in cultured human arterial smooth muscle cells by altering the expression of genes for proteoglycan core proteins. Diabetes 1999; 48: 616-22.

43. K. Sharma, F.N. Ziyadeh, B. Alzahabi, et al., Increased renal production of transforming growth factor-betal in patients with type II diabetes. Diabetes 1997; 46: 854-9.

44. E. Schonherr, H.T. Jarvelainen, L.J. Sandell, and T.N. Wight, Effects of plateletderived growth factor and transforming growth factor-beta 1 on the synthesis of a large versican-like chondroitin sulfate proteoglycan by arterial smooth muscle cells. J Biol Chem 1991; 266: 17640-7.

45. E. Schonherr, H.T. Jarvelainen, M.G. Kinsella, L.J. Sandell, and T.N. Wight, Platelet-derived growth factor and transforming growth factor-beta 1 differentially affect the synthesis of biglycan and decorin by monkey arterial smooth muscle cells. Arterioscler Thromb 1993; 13: 1026-36.

46. H. Dadlani, M.L. Ballinger, N. Osman, R. Getachew, and P.J. Little, Smad and p38 MAP kinase-mediated signaling of proteoglycan synthesis in vascular smooth muscle. J Biol Chem 2008; 283: 7844-52.

47. M.L. Burch, S.N. Yang, M.L. Ballinger, et al., TGF- $\beta$ stimulates biglycan synthesis via p38 and ERK phosphorylation of the linker region of Smad 2. Cell Mol Life Sci 2010 Accepted 12.02.2010.

48. J. Massague, S.W. Blain, and R.S. Lo, TGFbeta signaling in growth control, cancer, and heritable disorders. Cell 2000; 103: 295-309.

49. A. Agrotis, N. Kalinina, and A. Bobik, Transforming growth factor-beta, cell signaling and cardiovascular disorders. Curr Vasc Pharmacol 2005; 3: 55-61.

50. R. Derynck, and Y.E. Zhang, Smad-dependent and Smad-independent pathways in TGF-beta family signalling. Nature 2003; 425: 577-84.

51. L. Wu, and R. Derynck, Essential role of TGF-beta signaling in glucose-induced cell hypertrophy. Dev Cell 2009; 17: 35-48. 
52. A. Bobik, A. Agrotis, P. Kanellakis, et al., Distinct patterns of transforming growth factor-beta isoform and receptor expression in human atherosclerotic lesions. Colocalization implicates TGF-beta in fibrofatty lesion development. Circulation 1999; 99: 2883-91.

53. S.P. Evanko, E.W. Raines, R. Ross, L.I. Gold, and T.N. Wight, Proteoglycan distribution in lesions of atherosclerosis depends on lesion severity, structural characteristics, and the proximity of platelet-derived growth factor and transforming growth factor-beta. Am J Pathol 1998; 152: 533-46.

54. J. Massague, TGF-beta signal transduction. Annu Rev Biochem 1998; 67: 753-91.

55. W.M. Grady, Transforming growth factor-beta, Smads, and cancer. Clin Cancer Res 2005; 11: 3151-4.

56. Y. Taya, S. O'Kane, and M.W. Ferguson, Pathogenesis of cleft palate in TGFbeta3 knockout mice. Development 1999; 126: 3869-79.

57. J.J. Letterio, and A.B. Roberts, Transforming growth factor-beta1-deficient mice: identification of isoform-specific activities in vivo. J Leukoc Biol 1996; 59: 769-74.

58. D.G. Molin, M.C. DeRuiter, L.J. Wisse, et al., Altered apoptosis pattern during pharyngeal arch artery remodelling is associated with aortic arch malformations in Tgfbeta 2 knock-out mice. Cardiovasc Res 2002; 56: 312-22.

59. R. Derynck, J.A. Jarrett, E.Y. Chen, et al., Human transforming growth factor-beta complementary DNA sequence and expression in normal and transformed cells. Nature 1985; 316: 701-5.

60. N. Khalil, TGF-beta: from latent to active. Microbes Infect 1999; 1: 1255-63.

61. D.B. Rifkin, Latent transforming growth factor-beta (TGF-beta) binding proteins: orchestrators of TGF-beta availability. J Biol Chem 2005; 280: 7409-12.

62. C.M. Dubois, M.H. Laprise, F. Blanchette, L.E. Gentry, and R. Leduc, Processing of transforming growth factor beta 1 precursor by human furin convertase. $J$ Biol Chem 1995; 270: 10618-24.

63. J.P. Annes, J.S. Munger, and D.B. Rifkin, Making sense of latent TGFbeta activation. J Cell Sci 2003; 116: 217-24.

64. M.K. Lee, C. Pardoux, M.C. Hall, et al., TGF-beta activates Erk MAP kinase signalling through direct phosphorylation of ShcA. Embo J 2007; 26: 3957-67.

65. J.J. Dore, Jr., M. Edens, N. Garamszegi, and E.B. Leof, Heteromeric and homomeric transforming growth factor-beta receptors show distinct signaling and endocytic responses in epithelial cells. J Biol Chem 1998; 273: 31770-7.

66. S. Cheifetz, J.L. Andres, and J. Massague, The transforming growth factor-beta receptor type III is a membrane proteoglycan. Domain structure of the receptor. J Biol Chem 1988; 263: 16984-91.

67. S. Munir, G. Xu, Y. Wu, et al., Nodal and ALK7 inhibit proliferation and induce apoptosis in human trophoblast cells. J Biol Chem 2004; 279: 31277-86.

68. D. Javelaud, and A. Mauviel, Crosstalk mechanisms between the mitogenactivated protein kinase pathways and Smad signaling downstream of TGFbeta: implications for carcinogenesis. Oncogene 2005; 24: 5742-50.

69. A. Moustakas, S. Souchelnytskyi, and C.H. Heldin, Smad regulation in TGF-beta signal transduction. J Cell Sci 2001; 114: 4359-69.

70. J.W. Wu, M. Hu, J. Chai, et al., Crystal structure of a phosphorylated Smad2. Recognition of phosphoserine by the MH2 domain and insights on Smad function in TGF-beta signaling. Mol Cell 2001; 8: 1277-89. 
71. Y. Shi, A. Hata, R.S. Lo, J. Massague, and N.P. Pavletich, A structural basis for mutational inactivation of the tumour suppressor Smad4. Nature 1997; 388: 87-93.

72. F. Itoh, H. Asao, K. Sugamura, et al., Promoting bone morphogenetic protein signaling through negative regulation of inhibitory Smads. EMBO J 2001; 20: 4132-42.

73. M. Kretzschmar, J. Doody, I. Timokhina, and J. Massague, A mechanism of repression of TGFbeta/ Smad signaling by oncogenic Ras. Genes Dev 1999; 13: 804-16.

74. P.D. Richardson, M.J. Davies, and G.V. Born, Influence of plaque configuration and stress distribution on fissuring of coronary atherosclerotic plaques. Lancet 1989; 2: 941-4.

75. G. Camejo, E. Hurt-Camejo, O. Wiklund, and G. Bondjers, Association of apo B lipoproteins with arterial proteoglycans: pathological significance and molecular basis. Atherosclerosis 1998; 139: 205-22.

76. T.N. Wight, and M.J. Merrilees, Proteoglycans in atherosclerosis and restenosis: key roles for versican. Circ Res 2004; 94: 1158-67.

77. Y. Yamaguchi, D.M. Mann, and E. Ruoslahti, Negative regulation of transforming growth factor-beta by the proteoglycan decorin. Nature 1990; 346: 281-4.

78. M. Yanagishita, Function of proteoglycans in the extracellular matrix. Acta Pathol Jpn 1993; 43: 283-93.

79. C.L. Lendon, M.J. Davies, G.V. Born, and P.D. Richardson, Atherosclerotic plaque caps are locally weakened when macrophages density is increased. Atherosclerosis 1991; 87: 87-90.

80. M.J. Davies, P.D. Richardson, N. Woolf, D.R. Katz, and J. Mann, Risk of thrombosis in human atherosclerotic plaques: role of extracellular lipid, macrophage, and smooth muscle cell content. Br Heart J 1993; 69: 377-81.

81. S.T. Nikkari, H.T. Jarvelainen, T.N. Wight, M. Ferguson, and A.W. Clowes, Smooth muscle cell expression of extracellular matrix genes after arterial injury. Am J Pathol 1994; 144: 1348-56.

82. M.J. Davies, N. Woolf, and W.B. Robertson, Pathology of acute myocardial infarction with particular reference to occlusive coronary thrombi. Br Heart $J$ 1976; 38: 659-64.

83. K.J. Williams, G.M. Fless, K.A. Petrie, et al., Mechanisms by which lipoprotein lipase alters cellular metabolism of lipoprotein(a), low density lipoprotein, and nascent lipoproteins. Roles for low density lipoprotein receptors and heparan sulfate proteoglycans. J Biol Chem 1992; 267: 13284-92.

84. P.J. Little, M.L. Ballinger, M.L. Burch, and N. Osman, Biosynthesis of natural and hyperelongated chondroitin sulfate glycosaminoglycans: new insights into an elusive process. Open Biochem J 2008; 2: 135-42.

85. J. Boren, K. Olin, I. Lee, et al., Identification of the principal proteoglycanbinding site in LDL. A single-point mutation in apo-B100 severely affects proteoglycan interaction without affecting LDL receptor binding. $J$ Clin Invest 1998; 101: 2658-64.

86. C. Flood, M. Gustafsson, P.E. Richardson, et al., Identification of the proteoglycan binding site in apolipoprotein B48. J Biol Chem 2002; 277: 32228-33. 
87. H.F. Hoff, and W.D. Wagner, Plasma low density lipoprotein accumulation in aortas of hypercholesterolemic swine correlates with modifications in aortic glycosaminoglycan composition. Atherosclerosis 1986; 61: 231-6.

88. P. Libby, Inflammation in atherosclerosis. Nature 2002; 420: 868-74.

89. K. Dahl-Jorgensen, J.R. Larsen, and K.F. Hanssen, Atherosclerosis in childhood and adolescent type 1 diabetes: early disease, early treatment? Diabetologia 2005; 48: 1445-53.

90. T.N. Wight, Cell biology of arterial proteoglycans. Arteriosclerosis 1989; 9: 1-20.

91. L.E.M. Cardoso, P.J. Little, M.L. Ballinger, et al., Platelet-derived growth factor differentially regulates the expression and post-translational modification of versican by arterial smooth muscle cells through distinct protein kinase $\mathrm{C}$ and exracellular signal-regulated kinase pathways. J Biol Chem 2009; Epub 30.12.2009.

92. M.L. Ballinger, N. Osman, K. Hashimura, et al., Imatinib inhibits vascular smooth muscle proteoglycan synthesis and reduces LDL binding in vitro and aortic lipid deposition in vivo. Journal of Cellular and Molecular Medicine 2009; (in press).

93. M.E. Ivey, and P.J. Little, Thrombin regulates vascular smooth muscle cell proteoglycan synthesis via PAR-1 and multiple downstream signalling pathways. Thromb Res 2008.

94. M.L. Ballinger, M.E. Ivey, N. Osman, W.G. Thomas, and P.J. Little, Endothelin-1 activates ETA receptors on human vascular smooth muscle cells to yield proteoglycans with increased binding to LDL. Atherosclerosis 2009; 205: 4517.

95. S.N. Yang, M.L. Burch, R. Getachew, et al., Growth factor-mediated hyperelongation of glycosaminoglycan chains on biglycan requires transcription and translation. Arch Physiol Biochem 2009; 115: 147-54.

96. J. Nigro, R.J. Dilley, and P.J. Little, Differential effects of gemfibrozil on migration, proliferation and proteoglycan production in human vascular smooth muscle cells. Atherosclerosis 2002; 162: 119-29.

97. S.T. de Dios, K.V. Frontanilla, J. Nigro, et al., Regulation of the atherogenic properties of vascular smooth muscle proteoglycans by oral antihyperglycemic agents. J Diabetes Complications 2007; 21: 108-17. 